\title{
Analysis of Reflectivity and Shielding Effectiveness of Absorbing Material-Conductor Laminate for Electromagnetic Compatibility
}

\author{
Cheruku D. Raj ${ }^{1}$, Gottapu S. Rao ${ }^{2}$, Pappu V. Y. Jayasree ${ }^{1}$, Budumuru Srinu ${ }^{1}$, Pappula Lakshman ${ }^{1}$ \\ ${ }^{1}$ Department of ECE, GITAM Institute of Technology, GITAM University, Visakhapatnam, India; ${ }^{2}$ Department College of Engi- \\ neering, Andhra University, Visakhapatnam, India. \\ Email: dharmarajc@yahoo.com
}

Received February $2^{\text {nd }}, 2010$; revised March 29 $9^{\text {th }}, 2010$; accepted April $3^{\text {rd }}, 2010$.

\begin{abstract}
An absorbing material-conductor laminate is widely used for electromagnetic compatibility of electronic circuits at microwave frequencies. Such a laminate when properly designed will exhibit good results in terms of electromagnetic interference and compatibility. In this paper, microwave absorbing materials like 1) Ca-NiTi hexa ferrite composites $\left(\mathrm{Ca}(\mathrm{NiTi})_{x} \mathrm{Fe}_{12-2 x} \mathrm{O}_{19}\right)$ for $\left.x=0.4,2\right) \mathrm{M}$-Type Barium ferrites $\left(\mathrm{BaFe}_{12-2 x} A_{x} \mathrm{Co}_{x} \mathrm{O}_{19}\right.$ for the tetravalent $\mathrm{A}$ ions, $\mathrm{Ru}^{4+}$ is chosen), 3) MnZn ferrite-Rubber composites with volume fraction $v_{f}=0.4$, 4) Carbonyl-Iron particle composites with volume fraction $v_{f}=40 \%$ and conducting materials like copper, stainless steel are considered to form the interface in the laminate. Mathematical formulations are carried out for the estimation of reflectivity and shielding effectiveness of absorbing material-conductor laminate at microwave frequencies Analysis is also carried out for various thicknesses of the microwave absorbing material and conducting material in the laminate. The reflectivity and shielding effectiveness depends not only on the type of the selected material in the laminate, but also their thickness in the laminate and frequency of operation.
\end{abstract}

Keywords: Electromagnetic Compatibility, Reflectivity, Shielding Effectiveness, Propagation Constant, Attenuation Constant, Reflection Coefficient, Transmission Coefficient, Laminate, Interface

\section{Introduction}

Electromagnetic compatibility of an electronic circuit at microwave frequencies is of prime concern in the design of microwave circuits. External electromagnetic radiations should not interfere with the basic circuit performance and as well the circuit should not radiate electromagnetic energy to interfere with other neighboring circuits. The best method of achieving such an electromagnetic compatibility is to house the circuit in an enclosure made with a laminate which attenuates the radiations from the circuit and stops the external radiations interfering with the circuit. A laminate of microwave absorbing material-metallic conductor is considered to improve the electromagnetic compatibility capability of the circuit. This laminate is designed such that the radiation from the microwave circuit is attenuated to a very large extent before it propagates out of the circuit housing and simultaneously, also shields the microwave circuit from external radiation inferences. A well designed conducting metal with appropriate thickness provides the required shielding ability and a suitably selected microwave absorbing material with high attenuation constant arrests the radiations from the circuit. The thickness of the material layers in the laminate are so designed such that the reflectivity and shielding effectiveness of the laminate are achieved as per the requirement of the circuit compatibility considerations.

Reflectivity is nothing but the total reflection coefficient of the laminate looked from absorbing material layer direction and shielding effectiveness is the total attenuation offered by the laminate. Appropriate equations are derived for the determination of reflectivity and shielding effectiveness of the proposed laminate. Analysis is carried for the estimation of these parameters for different materials, thickness of the material layers and at different microwave frequencies. Various types of popularly available microwave absorbers and metals are considered for the laminate to give best performance in terms of reflectivity and shielding effectiveness. The thickness of the laminate is to be optimized for the required performance of the electromagnetic compatibility. 


\section{Reflectivity}

Reflectivity of the lamination can be estimated using the transmission line analysis for normal incidence. Reflection coefficient [1] at an interface of absorbing materialconducting metal can be given as

$$
\Gamma_{1}=\frac{\eta_{c}-\eta_{A}}{\eta_{c}+\eta_{A}}
$$

where $\eta_{c}$ is the intrinsic impedance of metallic conductor and $\eta_{A}$ is the intrinsic impedance of the microwave absorbing material.

The intrinsic impedance [2] of metallic conductor can be estimated as

$$
\eta_{c}=(1+j) \sqrt{\frac{\pi f \mu_{c}}{\sigma}}
$$

Where permeability of themetal, $\mu_{c}=\mu_{o} \mu_{r c}$

conductivity of the metal, $\sigma=\sigma_{o} \sigma_{r}$

$\mu_{r c}$ is relative permeability of the absorbing material, $\sigma_{r}$ is the relative conductivity of the conductor with respect to copper, $\mu_{o}$ is free space permeability, $\sigma_{o}$ is conductivity of copper and $f$ is the frequency of operation.

The intrinsic impedance of absorbing material can be derived to be

$$
\eta_{A}=\sqrt{\frac{-\left(2 \pi f \mu_{A}\right)^{2}}{\gamma_{A}^{2}}}
$$

Where $\mu_{A}$ is the permeability of absorbing material $=\mu_{o} \mu_{r A}, \mu_{r A}$ is relative permeability of absorbing material and $\gamma_{A}$ is the propagation constant of the absorbing material [3] which can be given as

$$
\begin{aligned}
\gamma_{A} & =j\left(\frac{2 \pi f}{c}\right) \sqrt{\mu_{r A} \in_{r A}} \\
& =j\left(\frac{2 \pi f}{c}\right) \sqrt{\left(\mu_{r A}^{\prime}-j \mu_{r A}^{\prime \prime}\right)\left(\epsilon_{r A}^{\prime}-j \in_{r A}^{\prime \prime}\right)}
\end{aligned}
$$

Relative permeability, $\mu_{r A}=\mu_{r A}^{\prime}-j \mu_{r A}^{\prime \prime}$

$c$ is the speed of light in free space.

The reflection coefficient at the interface of free spaceabsorbing material is very small and is neglected in this analysis.

The reflectivity at the interface of absorbing materialconducting metal in the laminate, as shown in the Figure $\mathbf{1}$, is the path loss of the electromagnetic energy while it propagates from free space to absorbing material-metal interface and back after reflection by the metal in the interface.

Thus, the reflectivity of the laminate can be derived as

$$
\begin{aligned}
r & =e^{-\alpha_{A} t_{A}} \Gamma_{1} e^{-\alpha_{A} t_{A}} \\
& =e^{-2 \alpha_{A} t_{A}} \Gamma_{1}
\end{aligned}
$$

Where $t_{A}$ is the thickness of the absorbing material and $\alpha_{A}$ is the attenuation constant of the absorbing material [3] can be given as

Reflectivity expressed in $d B$ is

$$
R=20 \log _{10}(r) \quad d B
$$

\section{Shielding Effectiveness}

Shielding effectiveness of the laminate of microwave absorbing material and conducting metal is the total attenuation loss of the electromagnetic energy while it propagates through the interface. In other words, the shielding effectiveness is nothing but transmission coefficient of the interface of microwave absorbing material and conducting metal in the laminate.

The transmission coefficient of the interface at two boundaries (absorber-conductor \& conductor-free space) [2] is given as

$$
p=\frac{8 \eta_{o} \eta_{A} \eta_{c}}{\left(\eta_{o}+\eta_{A}\right)\left(\eta_{A}+\eta_{c}\right)\left(\eta_{c}+\eta_{o}\right)}
$$

Where $\eta_{o}$ is the free space intrinsic impedance $=120 \pi$ ohms.

Reflection coefficient [2] at absorbing material-metal interface, $q_{1}$ and that at conductor-free space interface $q_{2}$ can be given as

$$
\begin{aligned}
& q_{1}=\frac{\left(\eta_{A}-\eta_{o}\right)\left(\eta_{A}-z(c)\right)}{\left(\eta_{A}+\eta_{o}\right)\left(\eta_{A}+z(c)\right)} \\
& q_{2}=\frac{\left(\eta_{c}-\eta_{A}\right)\left(\eta_{c}-\eta_{o}\right)}{\left(\eta_{c}+\eta_{A}\right)\left(\eta_{c}+\eta_{o}\right)}
\end{aligned}
$$

where $z(c)$, impedance to the right of the absorber-metal interface and can be derived as

$$
\alpha_{A}=\frac{\sqrt{2} \pi f}{c} \sqrt{\left(\mu_{r A}^{\prime \prime} \epsilon_{r A}^{\prime \prime}-\mu_{r A}^{\prime} \epsilon_{r A}^{\prime}\right)+\sqrt{\left(\mu_{r A}^{\prime \prime} \epsilon_{r A}^{\prime \prime}-\mu_{r A}^{\prime} \epsilon_{r A}^{\prime}\right)^{2}+\left(\epsilon_{r A}^{\prime} \mu_{r A}^{\prime \prime}+\epsilon_{r A}^{\prime \prime} \mu_{r A}^{\prime}\right)^{2}}}
$$




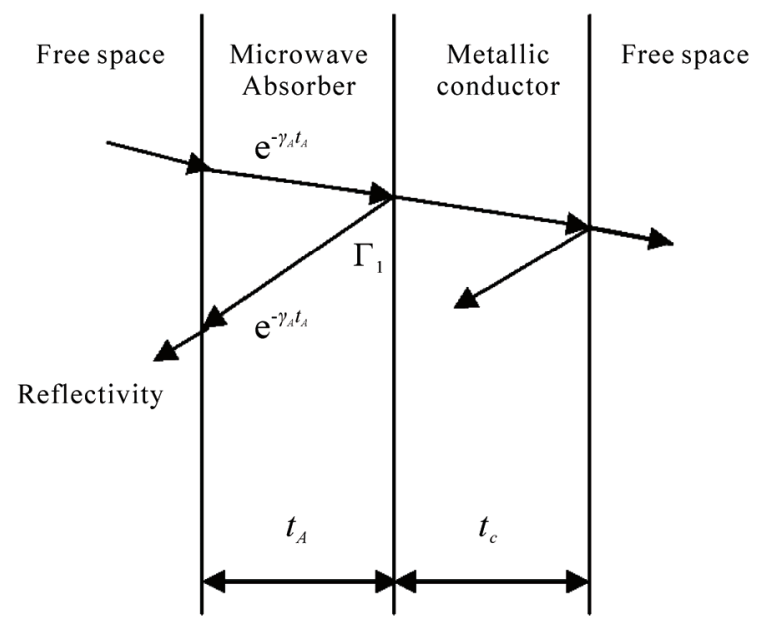

Figure 1. Reflectivity of microwave absorber-conductor laminate

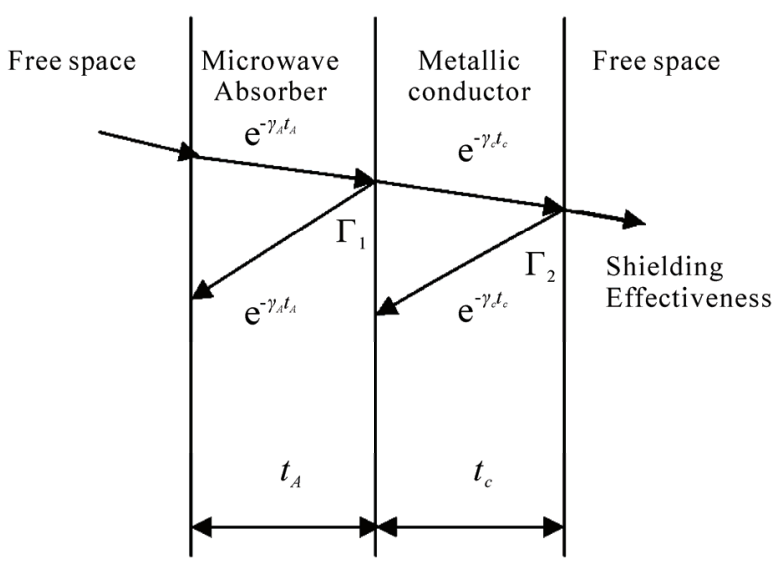

Figure 2. Shielding effectiveness of microwave absorberconductor laminate

$$
z(c)=\eta_{c}\left(\frac{\eta_{o} \cosh \left(\gamma_{c} t_{c}\right)+\eta_{c} \sinh \left(\gamma_{c} t_{c}\right)}{\eta_{c} \cosh \left(\gamma_{c} t_{c}\right)+\eta_{o} \sinh \left(\gamma_{c} t_{c}\right)}\right)
$$

$t_{c}$ is thickness of the metallic conductor and $\gamma_{c}$ is the propagation constant in the metallic conductor [2] given as

$$
\gamma_{c}=(1+j) \sqrt{\pi f \mu \sigma}
$$

The total transmission coefficient [2] across the laminate of the two interfaces can thus be derived to be

$$
T=p\left[\left(1-q_{1} e^{-2 \gamma_{A} t_{A}}\right)\left(1-q_{2} e^{-2 \gamma_{c} t_{c}}\right)\right]^{-1} e^{-\gamma_{A} t_{A}-\gamma_{c} t_{c}}
$$

The Shielding effectiveness of the microwave absorbing material-metal laminate can thus be given in decibels as

$$
S=-20 \log _{10}(T) \quad d B
$$

\section{Results and Conclusions}

Analysis is carried out for the estimation of reflectivity (equation 11) of the laminate of microwave absorbing material-metallic conductor for various types of absorbing materials, conducting materials and thickness of material layers in the laminate. Popular and widely used microwave absorbing materials like 1) Ca-NiTi hexa ferrite composites $\left(\mathrm{Ca}(\mathrm{NiTi})_{\mathrm{x}} \mathrm{Fe}_{12-2 \mathrm{x}} \mathrm{O}_{19}\right)$ for $\left.\mathrm{x}=0.4[4], 2\right)$ M-Type Barium ferrites $\left(\mathrm{BaFe}_{12-2 \mathrm{x}} \mathrm{A}_{\mathrm{x}} \mathrm{Co}_{\mathrm{x}} \mathrm{O}_{19}\right.$ for the tetravalent $\mathrm{A}$ ions, $\mathrm{Ru}^{4+}$ is chosen) [5], 3) $\mathrm{MnZn}$ ferriteRubber composites with volume fraction $\mathrm{v}_{\mathrm{f}}=0.4$ [6] and 4) Carbonyl-Iron particle composites with volume fraction $\mathrm{v}_{\mathrm{f}}=40 \%[3,7]$ along with copper as conductor is considered for the estimation of optimum reflectivity.

Figures 3 \& 4 show the variations of reflectivity (equation 11) with frequency for different absorbing materials at a thickness of 5 and $10 \mathrm{~mm}$ respectively. Figures $5 \& 6$ are the plots for variations of reflectivity with thickness of layer of absorbing materials $\left(\mathrm{BaFe}_{12-2 \mathrm{x}} \mathrm{A}_{\mathrm{x}} \mathrm{Co}_{\mathrm{x}}\right.$ $\mathrm{O}_{19}$ for the tetravalent $\mathrm{A}$ ions, $\mathrm{Ru}^{4+}$ is chosen and ferriteRubber composites with volume fraction $\mathrm{v}_{\mathrm{f}}=0.4$ ) at different frequencies. Reflectivity is estimated at $12 \mathrm{GHz}$ for various absorbing materials at different thicknesses and is presented as in Figure 7.

Reflectivity of the laminate mainly depends upon the absorption properties of the microwave absorbing material and its thickness. Thus, the microwave absorbing material, M-Type Barium ferrites exhibits excellent reflectivity (around $20 \mathrm{~dB}$ better than Carbonyl-Iron particle composites with volume fraction $\mathrm{v}_{\mathrm{f}}=40 \%$ ) over the entire frequency range compared to other types of absorbing materials. Since attenuation constant is very high for that of M-Type Barium ferrites.

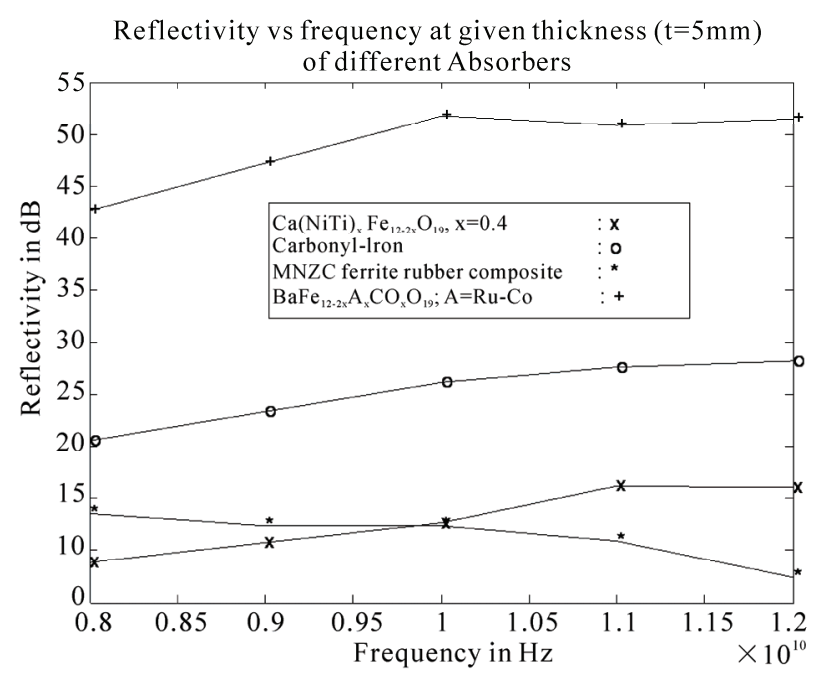

Figure 3. The variation of the reflectivity as a function of frequency for different microwave absorbers at absorber thickness of $5 \mathbf{~ m m}$ 


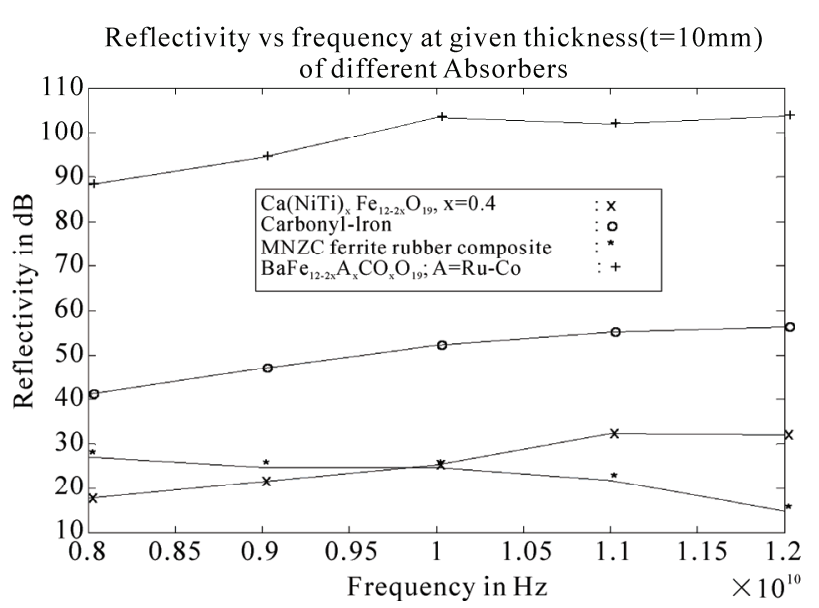

Figure 4. The variation of the reflectivity as a function of frequency for different microwave absorbers at absorber thickness of $10 \mathrm{~mm}$

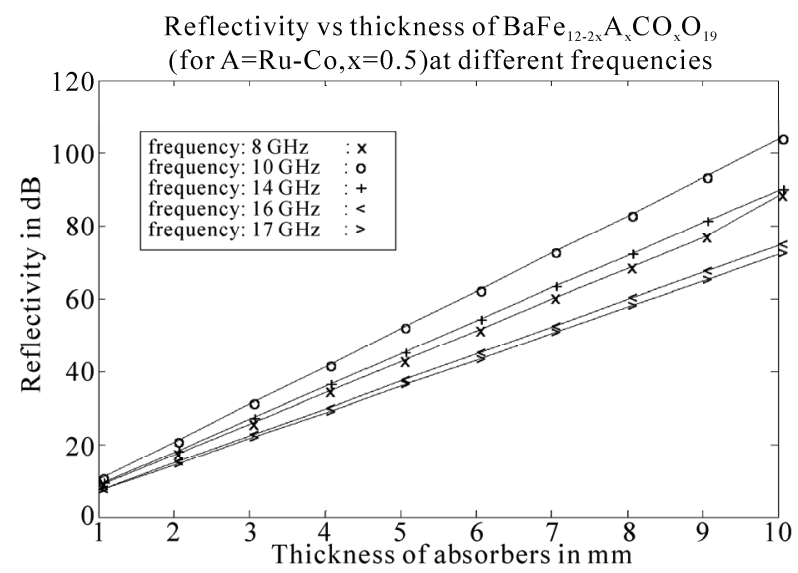

Figure 5. The variation of the reflectivity as a function of hickness for the $\mathrm{BaFe}_{12-2 \mathrm{x}} \mathrm{A}_{\mathrm{x}} \mathrm{Co}_{\mathrm{x}} \mathrm{O}_{19}$-copper laminate at different frequencies

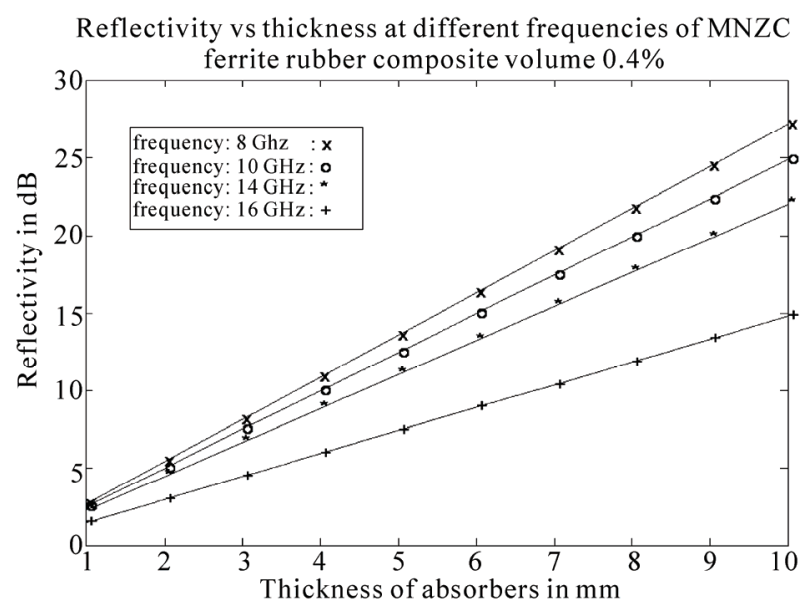

Figure 6. The variation of the reflectivity as a function of thickness for the MnZn ferrite-Rubber composite-copper laminate at different frequencies

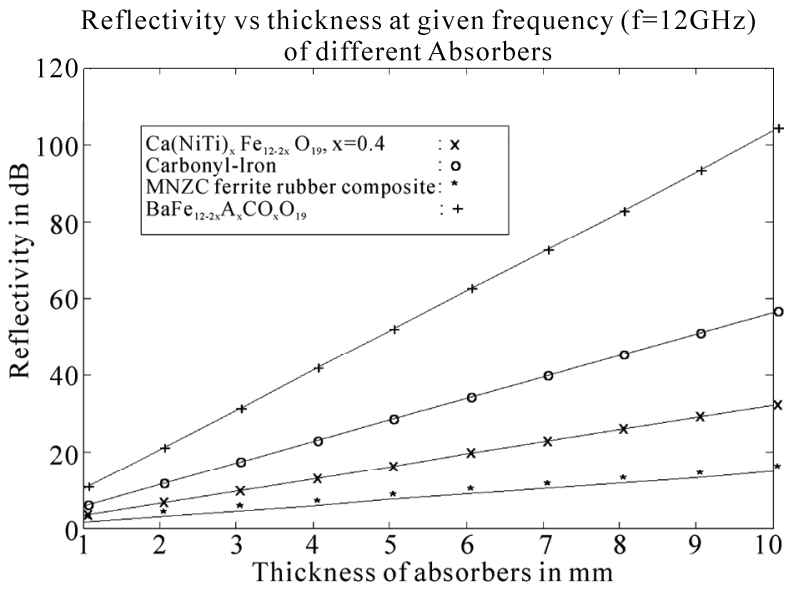

Figure 7. The variation of the reflectivity as a function of thickness for different microwave absorbers at $12 \mathbf{~ G H z}$ frequency

It can also be deduced that the reflectivity of $\mathrm{BaFe}_{12-2 x}$ $\mathrm{A}_{\mathrm{x}} \mathrm{Co}_{\mathrm{x}} \mathrm{O}_{19}$ for the tetravalent $\mathrm{A}$ ions, $\mathrm{Ru}^{4+}$ is chosen and $\mathrm{MnZn}$ ferrite-Rubber composites with volume fraction $\mathrm{v}_{\mathrm{f}}=0.4$ is better by approximately $20 \mathrm{~dB}$ in the $\mathrm{X}$-band range of frequencies and it decreases at high frequencies.

Investigations are carried out to determine the shielding effectiveness (Equation (18)) of the laminate of microwave absorbing material-metal for different combinations of materials at different thicknesses of layers in the laminate. Figures $8 \& 9$ are the plots for variation of shielding effectiveness of laminate of $\mathrm{BaFe}_{12-2 \mathrm{x}} \mathrm{A}_{\mathrm{x}} \mathrm{Co}_{\mathrm{x}} \mathrm{O}_{19}$ (for the tetravalent $\mathrm{A}$ ions, $\mathrm{Ru}^{4+}$ is chosen) and $\mathrm{MnZn}$ ferrite- Rubber composites with volume fraction $\mathrm{v}_{\mathrm{f}}=0.4$ for 1,5 and $10 \mathrm{~mm}$ thicknesses of absorbing material and 1 mil layer thickness of copper respectively. Figures 10 $\& \mathbf{1 1}$ are the plots for variation of shielding effectiveness of laminate of $\mathrm{BaFe}_{12-2 x} \mathrm{~A}_{\mathrm{x}} \mathrm{Co}_{\mathrm{x}} \mathrm{O}_{19}$ (for the tetravalent $\mathrm{A}$ ions, $\mathrm{Ru}^{4+}$ is chosen) and MnZn ferrite-Rubber composites with volume fraction $\mathrm{v}_{\mathrm{f}}=0.4$ for 1,5 and $10 \mathrm{~mm}$ thicknesses of absorbing material and 1 mil layer thickness of stainless steel respectively.

Shielding effectiveness is also estimated for different layer thicknesses of the copper in the laminate and is presented in Figures $12 \& \mathbf{1 3}$ for microwave absorbing material layer of $\mathrm{BaFe}_{12-2 \mathrm{x}} \mathrm{A}_{\mathrm{x}} \mathrm{Co}_{\mathrm{x}} \mathrm{O}_{19}$ for $\mathrm{A}=\mathrm{Ru}^{4+}, \mathrm{MnZn}$ ferrite-Rubber composites with volume fraction $\mathrm{v}_{\mathrm{f}}=0.4$ for $\mathrm{x}=0.4$ (thickness of the absorbing material $=5 \mathrm{~mm}$ ). The plot of shielding effectiveness with frequency for different absorbing materials of the interface with copper as conducting layer material is shown in Figure 14.

The shielding effectiveness of the conductor dominates that of microwave absorbing material in the laminate and this in turn depends on the thickness of the conducting layer almost linearly. This is because the attenuation constant of the conductor is extremely high 


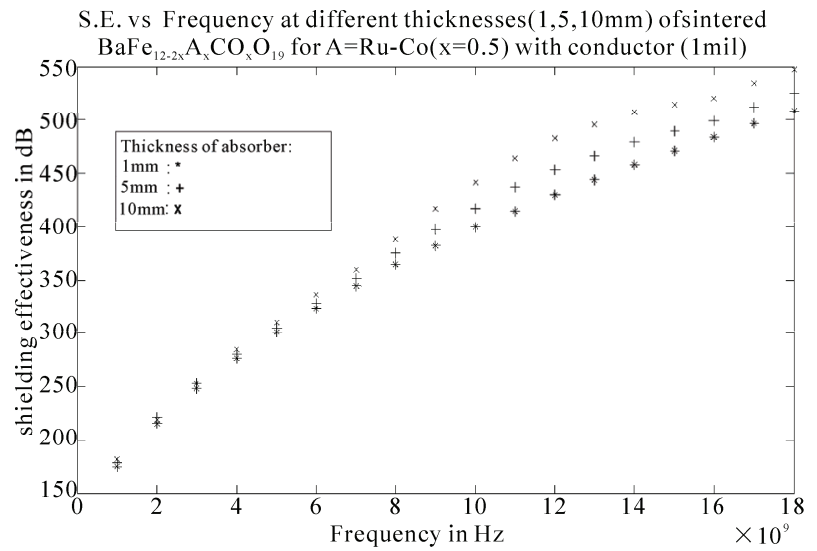

Figure 8. The variation of the Shielding effectiveness as a function of frequency of $\mathrm{BaFe}_{12-2 \mathrm{x}} \mathrm{A}_{\mathrm{x}} \mathrm{Co}_{\mathrm{x}} \mathrm{O}_{19}$-copper laminate for different thicknesses of microwave absorber

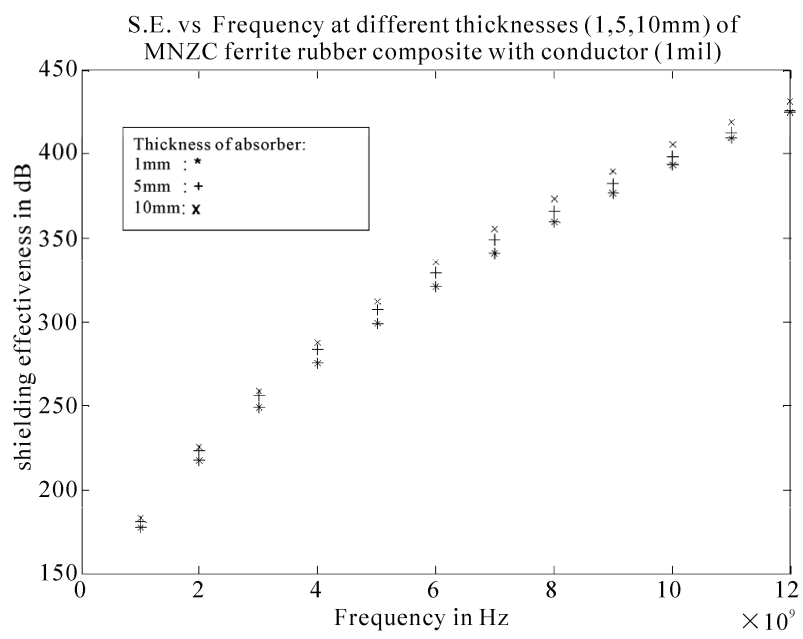

Figure 9. The variation of the S.E as a function of frequency of MnZn ferrite-Rubber composites-copper laminate for different thicknesses of microwave absorber

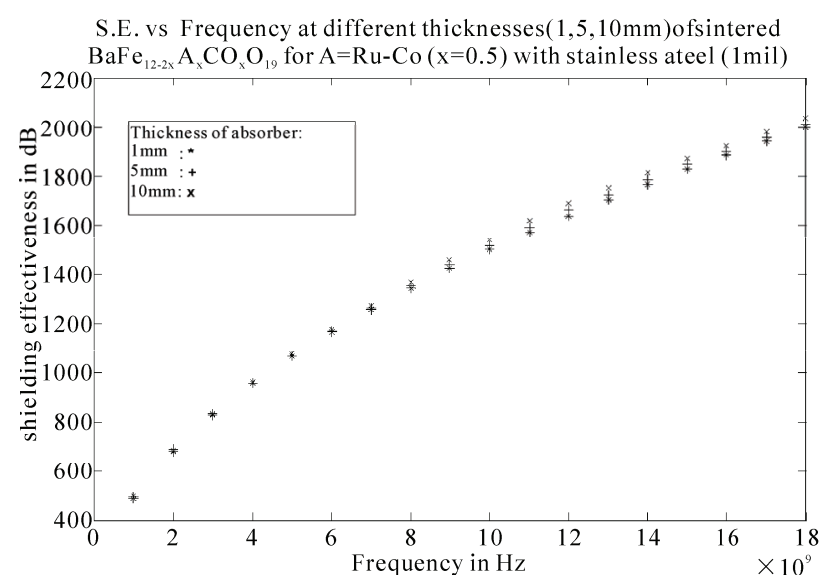

Figure 10. The variation of the Shielding effectiveness as a function of frequency of $\mathrm{BaFe}_{12-2 x} \mathrm{~A}_{\mathrm{x}} \mathrm{Co}_{\mathrm{x}} \mathrm{O}_{19}$-stainless steel laminates for different thicknesses of microwave absorber

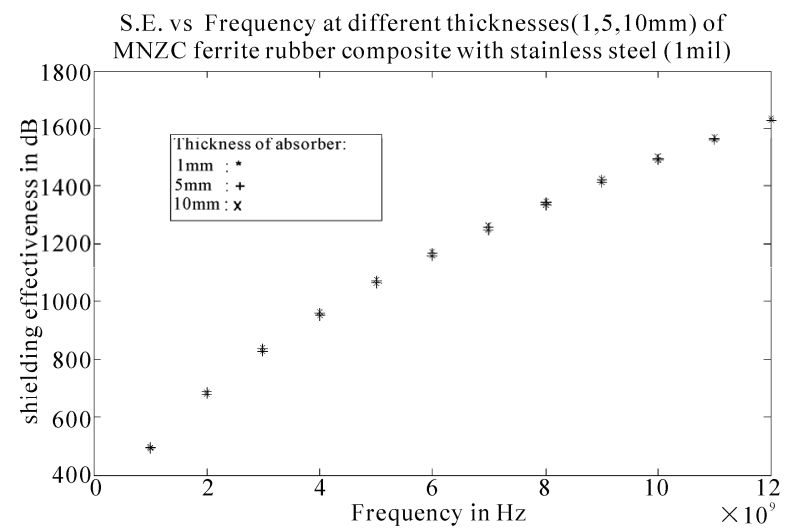

Figure 11. The variation of the Shielding effectiveness as a function of frequency of MnZn ferrite-Rubber compositesstainless steel laminate for different thicknesses of microwave absorber

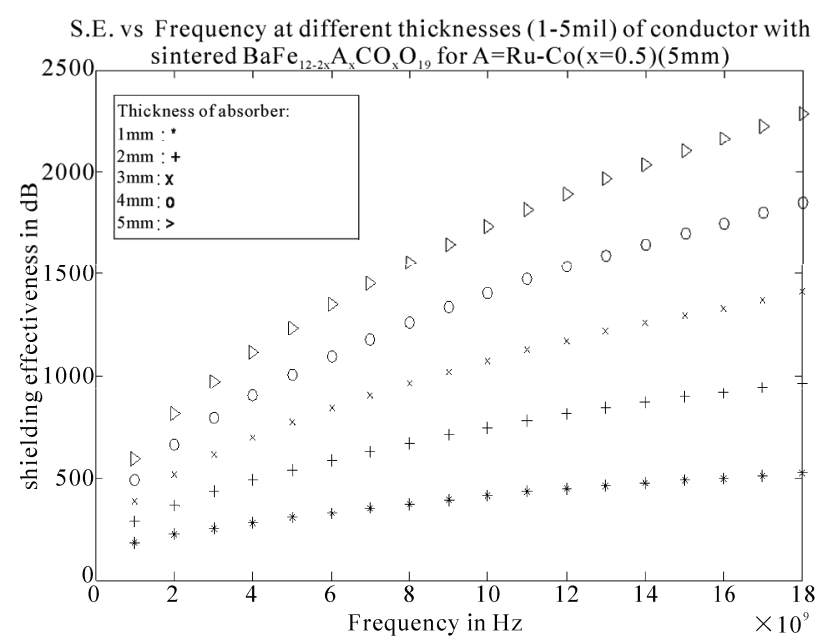

Figure 12. The variation of the Shielding effectiveness as a function of frequency of $\mathrm{BaFe}_{12-2 \mathrm{x}} \mathrm{A}_{\mathrm{x}} \mathrm{Co}_{\mathrm{x}} \mathrm{O}_{19}$-copper for different thicknesses of copper

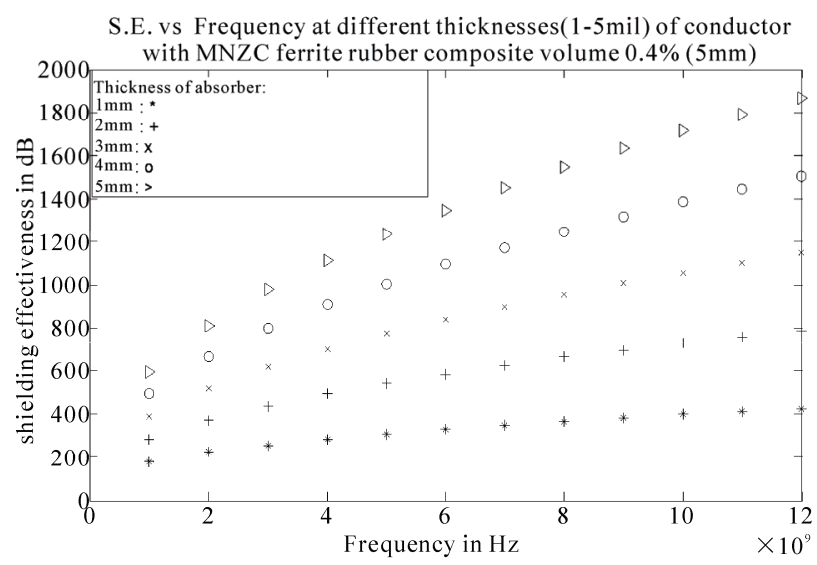

Figure 13. The variation of the Shielding effectiveness as a function of frequency of MnZn ferrite-Rubber compositescopper for different thicknesses of copper 


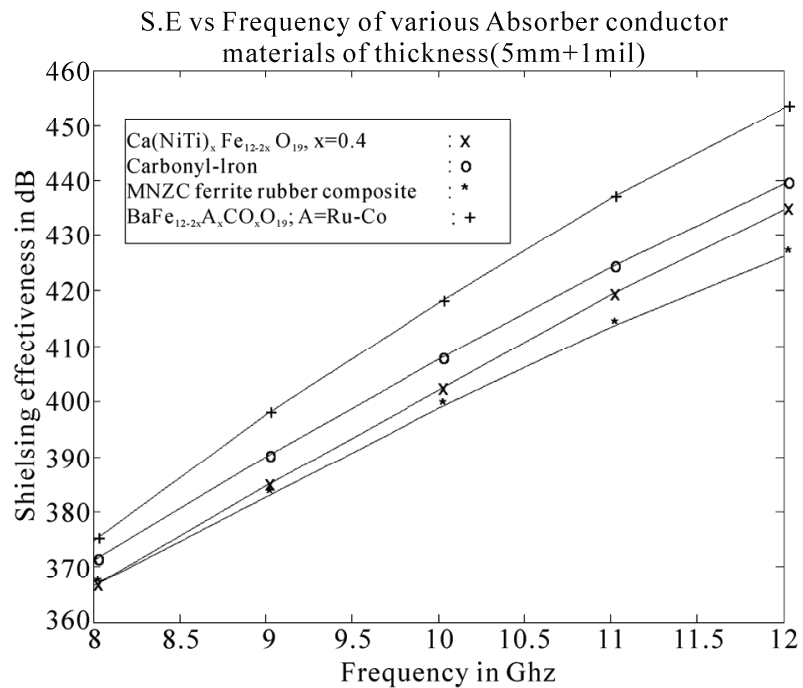

Figure 14. Comparison of shielding effectiveness of different absorbers as a function of frequency

compared that of the absorbing material. The shielding effectiveness of the laminate using stainless steel as conducting layer is much higher than that of a laminate using copper as conducting material layer.

From the above analysis for reflectivity and shielding effectiveness, it may be deduced that laminate comprising of M-Type Barium ferrites as absorbing material layer and stainless steel as conducting material layer exhibits very good reflectivity as well as shielding effectiveness characteristics. It may be concluded that the reflectivity and shielding effectiveness primarily depend upon the material characteristics. The thickness of the material can be selected for a given application according to the requirements of the problem and subject to the availability of the materials and mechanical constraints of the circuit under consideration.

\section{Acknowledgements}

We thank the management of GITAM University for all the support and encouragement rendered in this project. We also extend our thanks to the Vice Chancellor and Registrar of GITAM University for providing the required facilities for carrying out this work. Our sincere thanks are also due to the Principal of GITAM Institute of Technology, Head of the Department of E.C.E and its staff for their kind support.

\section{REFERENCES}

[1] V. P. Kodali, "Engineering Electromagnetic Compatibility, Principles, Measurements and Technologies," S Chand and Company Ltd., 2000.

[2] R. B. Schulz, V. C. Plantz and D. R. Brush, "Shielding Theory and Practice," IEEE Transactions on Electromagnetic Compatibility, Vol. 30, No. 3, August 1988, pp 187-201.

[3] Y. B. Feng, T. Qiu, X. Y. Li and C. Y. Shen, "Microwave Absorption Properties of the Carbonyl Iron/ EPDM Radar Absorbing Materials," Journal of Wuhan University of Technology Materials Science Edition, Vol. 22, No. 2, June 2007, pp. 266-270.

[4] P. Singh, V. K. Babbar, A. Razdan, S. L. Srivastava and T. C. Goel, "Microwave Absorption Studies of Ca-Niti Hexaferrite Composites in X-Band," Materials Science and Engineering, Vol. 78, No. 2-3, 2000, pp. 70-74.

[5] H.-S. ChO and S.-S. Kim, "M-Hexa ferrites with Planar Magnetic Anisotropy and Their Application to HighFrequency Microwave Absorbers," IEEE Transactions on Magnetics, Vol. 35, No. 5, September 1999, pp. 31513153.

[6] D. Y. Kim, Y. C. Chung, T. W. Kang and H. C. Kim, "Dependence of Microwave Absorbing Property on Ferrite Volume Fraction in MnZn Ferrite-Rubber Composites," IEEE Transactions on Magnetics, Vol. 32, No. 2, March 1996, pp. 555-558.

[7] B. S. Zhang, Y. Feng, J. Xiong, Y. Yang and H. X. Lu, "Microwave-Absorbing Properties of De-Aggregated Flake-Shaped Carbonyl-Iron Particle Composites at 2-18 GHz," IEEE Transactions on Magnetics, Vol. 42, No. 7, July 2006, pp. 1178-1781. 